\title{
Environmental safety management of urban building by regulation of formation process of exhaust gases of motor vehicles
}

\author{
Liparit Badalyan ${ }^{1}$, Vladimir Kurdjukov ${ }^{2}$, and Alla Ovcharenko ${ }^{1, *}$ \\ ${ }^{1}$ DSTU, Technological Processes and Productions Safety Department, 1 Gagarina Sq, Rostov-on- \\ Don, Russian Federation \\ ${ }^{2}$ DSTU Management and Business Technologies Department, 1 Gagarina Sq, Rostov-on-Don, \\ Russian Federation
}

\begin{abstract}
Modern development of the construction industry involves accounting and assessment of operating conditions of structures. Excessive technological environmental impact can lead to economic losses and a decrease in the efficiency of investment projects in construction. Mobile sources emission record is an important component of the ecosystem state diagnosis in modern cities. For scientifically substantiated and reliable determination of the mass flow of the motor vehicles pollutants it is necessary to take into account the mixture formation and combustion of the working mixture in the internal combustion engine. The article describes the authors' approach to calculating the volumetric flow rate of exhaust gases based on the characteristics of the vehicle's transport operations available for operational control. Studies have shown that, when using a particular fuel, the determination of the volume flow rate of exhaust gases can be reduced to finding the power of the engine. In addition, the composition changes of the fuel (or fuel replacement) and the regulation of the effective power of the engine (by organization of traffic) allow to influence on the volume and composition of the emission of exhaust gases of vehicles and on the pollution of the urban environment in general. The results of the studies make it easier to calculate the mass of pollutant emissions by the transport stream into the outer air and can be used as preliminary data to assess the negative anthropogenic impact on the ecosystem.
\end{abstract}

\section{Introduction}

In the conditions of the ecological crisis, which is a characteristic of the majority of large cities of the Russian Federation, an important task of local administrations is the assessment of the environmental state in all spheres of anthropogenic activity. First of all, it is necessary to develop a system for monitoring the permissible level of negative impact on a densely resided urban population. Equally important is the environmental safety of

\footnotetext{
* Corresponding author: alunia_020788@mail.ru
} 
buildings, both during construction and operation. An acceptable balance between economic activity and comfortable living conditions of organisms in urbanized landscapes can be achieved through the use of reliable information on environmental pollution. In this regard, it is important to estimate the mass emissions of vehicles and to have the ability of reducing the toxic and carcinogenic substances emission. The determination of the volume flow of exhaust gases should be considered an important stage of the calculation of pollutant emissions. This is a complex task that requires improving the methods of mathematical modeling of the processes of mixture formation and combustion of a working mixture, a modern experimental base, financing, etc.

The authors propose a method for calculating the volume flow rate of exhaust gases depending on the characteristics of the vehicle's transport operations available for operational control. Understanding the process of exhaust gases formation will allow to influence the composition of emissions of pollutants by motor vehicles and achieve the required quality of the urban environment.

\section{Methods}

Assessment of pollutants emission is based on the patterns of change in the volume flow rate of exhaust gases. Calculations are complicated by the use of inconvenient for monitoring engine characteristics: air pressure and temperature at suction (for unblown engines) and after the refrigerator and compressor (for pressure-charged engines), the polytropic index of air compression, etc. $[1,2]$.

The air flow in the internal combustion engine can be represented by the formula [1]

$$
Q_{\text {в }}=\frac{k_{\text {атм }}}{\tau_{\mathrm{T}}} \cdot \frac{p}{T} k_{\mathrm{B}} V n,
$$

where $Q_{b}$ is the air-quantity flow, $\mathrm{m}^{3} / \mathrm{s} ; k_{\text {ams }}$ - factor taking into account atmospheric conditions, $\mathrm{K} / \mathrm{MPa} ; \tau_{m}$ - cycle (number of strokes) of the engine; $p$ - air pressure at suction to the engine, $\mathrm{MPa} ; T$ - air temperature at suction to the engine, $\mathrm{K} ; k_{b}$ - air consumption coefficient, taking into account the design features of the engine; $V$ is the volume of cylinders, $\mathrm{m}^{3} ; n$ - crankshaft speed, $\mathrm{s}^{-1}$.

For engines without blowing the cylinders with air, the filling factor of the cylinder $\eta_{\mathrm{v}}$ is used instead of $k_{\mathrm{B}}$; for engines with blowing of cylinders by air - blowdown factor $\varphi$.

Taking into account the equality of the molar volumes of any gases, the exhaust gases volume flow corresponding to the completeness of combustion of fuel has the form

$$
Q_{\mathrm{O} \Gamma}=\beta Q_{\mathrm{B}},
$$

where $Q_{\mathrm{O}}$ is the volume flow of exhaust gases, $\mathrm{m}^{3} / \mathrm{s} ; \beta$ is the theoretical (chemical) coefficient of molecular change in the combustible mixture.

Combining formulas (1) and (2) one obtains an expression for calculating the volume flow of exhaust gases in a general form, $\mathrm{m}^{3} / \mathrm{s}$

$$
Q_{\text {ОГ }}=\frac{k_{\text {атм }}}{\tau_{\mathrm{T}}} \varphi \beta \frac{p}{T} \eta_{V} V n
$$

In turn, the formula of effective power [2, 3] after certain transformations can be represented as follows 


$$
N_{e}=\frac{H_{u} \rho_{3} \eta_{e}}{\tau_{\mathrm{T}} \mu \alpha L_{0}} \eta_{V} V n,
$$

where $H_{u}$ is the value of the net calorific value of $1 \mathrm{~kg}\left(\right.$ or $1 \mathrm{~m}^{3}$ ) of fuel, $\mathrm{J} / \mathrm{kg}($ or $\mathrm{J} / \mathrm{m} 3$ ); $\rho_{3}$ - charge density at the inlet, $\mathrm{kg} / \mathrm{m}^{3} ; \eta_{e}$ - effective efficiency of the engine; $\alpha$ - coefficient of excess air; $L_{0}$ is the theoretically required amount of air in kmol for complete combustion of $1 \mathrm{~kg}$ of liquid fuel, $\mathrm{kmol} / \mathrm{kg}$, or for combustion of $1 \mathrm{kmol}$ (or $1 \mathrm{~m}^{3}$ ) of gaseous fuel, $\mathrm{kmol} / \mathrm{kmol}\left(\right.$ or $\left.\mathrm{m}^{3} / \mathrm{m}^{3}\right)[1,2]$.

During pressure-charged engines operating, air enters the cylinder from the compressor or cooler, so the air pressure and temperature $\left(p_{\mathrm{K}}\right.$ и $\left.T_{\mathrm{K}}\right)$ are taken at the exit of the compressor or cooler. In aspirate engines, the pressure and temperature of the air are denoted by $p_{0}$ and $T_{0}$. The charge density for engines with or without supercharging can be found from the expressions

$$
\rho_{\text {к }}=\frac{10^{6} p_{\text {к }}}{R T_{\text {к }}} \text { или } \rho_{0}=\frac{10^{6} p_{0}}{R T_{0}}
$$

where $R$ is the gas constant per $1 \mathrm{~kg}$ of gas, $R=(8312 / \mu) \mathrm{J} /(\mathrm{kg} \cdot \mathrm{K})[3](\mu-$ mass of $1 \mathrm{kmol}$ of gas, $\mathrm{kg} / \mathrm{kmol})$.

The current value of the excess air factor is advisable to represent in relative units, i.e. $\bar{\alpha}$ and $\bar{N}$ correspondingly. The transformation of $\alpha$ and $N_{e}$ into the parameters to be coded is carried out according to the formulas

$$
\bar{\alpha}=\frac{\alpha-\alpha_{\min }}{\alpha_{\max }-\alpha_{\min }}
$$

where $\alpha_{\min }$ and $\alpha_{\max }$ are the minimum and maximum values of the excess air coefficient, respectively. For compression-ignition engines, $\alpha_{\min }$ corrresponds to the nominal mode ( $\left.\alpha_{\text {ном }}\right), \alpha_{\max }$ - the engine is stable at idle $\left(\alpha_{\mathrm{xx}}\right) ; \alpha_{\text {max }}$ for motors with positive ignition $\alpha_{\min }$ corresponds to idle $\left(\alpha_{\mathrm{xx}}\right)$, - nominal mode $\left(\alpha_{\text {ном }}\right)$. In the general form $\alpha=\bar{\alpha}\left(\alpha_{\max }-\alpha_{\min }\right)+\alpha_{\min }$.

$$
\bar{N}=\frac{N-N_{\min }}{N_{\max }-N_{\min }},
$$

where $N_{\max }$ and $N_{\min }$ - the maximum and minimum engine power. Bearing in mind that $N_{\max }$ corresponds to the nominal power $N_{\text {ном, }}, \mathrm{W}$, and $N_{\text {min }}$ - idle power $N_{\text {xx }}, \mathrm{W}$, the current effective power value can be represented as $N_{e}=\bar{N}\left(N_{\text {ном }}-N_{\text {xх }}\right)+N_{\text {xх }}$.

\section{Results}

We express $\eta_{V} V n$ from (4) and substitute it in (3). Taking into account (5) and some approximations, we will represent the volume flow of exhaust gases of an internal combustion engine in a general form

$$
Q_{\text {ОГ }}=8,312 \cdot 10^{3} k_{\text {атм }} \varphi \beta \frac{L_{0}}{H_{u}} \cdot \frac{\alpha N_{e}}{\eta_{e}} .
$$

Taking into account the formulas $(6,7)$, expression (8) is the following 


$$
Q_{\text {ОГ }}=8,312 \cdot 10^{3} k_{\text {атм }} \varphi \beta \frac{L_{0}}{H_{u}} \cdot \frac{\left[\bar{\alpha}\left(\alpha_{\max }-\alpha_{\min }\right)+\alpha_{\min }\right] \cdot\left[\bar{N}\left(N_{\text {ном }}-N_{\text {хх }}\right)+N_{\text {хх }}\right]}{\eta_{e}} .
$$

For different types of fuel the theoretical coefficient of molecular change in the combustible mixture is determined by formulas in Table 1 .

Table 1. Definition formulas of $\beta$ for different types of fuel

\begin{tabular}{|c|c|c|c|c|}
\hline $\begin{array}{c}\text { Type of } \\
\text { fuel }\end{array}$ & $\begin{array}{c}\text { Range of } \\
\text { change } \alpha\end{array}$ & Formula & $\begin{array}{c}\text { № of } \\
\text { formula }\end{array}$ & $\begin{array}{c}\text { Source of } \\
\text { information }\end{array}$ \\
\hline \multirow{2}{*}{ Liquid } & $\alpha \geq 1$ & $\beta=1 \pm \frac{H}{4 \alpha L_{0}}$ & 10 & {$[1]$} \\
\cline { 2 - 5 } & $\alpha<1$ & $\beta=0,792\left(1 \pm \frac{5 H}{4 \alpha L_{0}}\right)$ & 11 & {$[4]$} \\
\hline \multirow{2}{*}{ Gaseous } & - & $\beta=1 \pm \frac{\sum\left(\frac{m}{4}+\frac{r}{2}-1\right) \mathrm{C}_{n} \mathrm{H}_{m} O_{r}}{\alpha L_{0}+1}$ & 12 & {$[2]$} \\
\hline
\end{tabular}

In formulas (7-9) $H$ is the volume fraction of hydrogen in $1 \mathrm{~kg}$ of liquid fuel, $\mathrm{kmol} / \mathrm{kg}$.

For liquid fuel, plus and minus signs refer to wet and dry exhaust gases, for gaseous fuels - to natural and generator gases, respectively. For pressure-charged engines, a total excess air ratio $\varphi \cdot \alpha$ is used instead of $\alpha$.

When driving cars in the urban cycle for diesel engines, one can take $\alpha>1$ and use formula (7) when determining $\beta$; for gasoline engines most often $\alpha \leq 1$ and $\beta$ is calculated by formula (11).

In the expression (12), $\mathrm{C}_{n} \mathrm{H}_{m} \mathrm{O}_{r}$ is the volume fraction of each gas entering into $1 \mathrm{kmol}$ or $1 \mathrm{~m}^{3}$ of gaseous fuel, $\mathrm{kmol} / \mathrm{kmol}$ or $\mathrm{m}^{3} / \mathrm{m}^{3} ; n, m, r$ is the number of carbon atoms (C), hydrogen $(\mathrm{H})$, oxygen $(\mathrm{O})$, respectively.

In practical calculations, it is convenient to use reference data for the quantities of theoretically required air quantity, lowest heat of combustion, and the average values of the elements that make up liquid and gaseous fuels. The average values of the constant characteristics of the composition of the fuel are given in Tables 2 to 4 .

Table 2. Numerical values of $L_{0}$ and $H_{u}$ for different types of fuels $[2,5]$

\begin{tabular}{|c|c|c|c|c|}
\hline \multirow{2}{*}{ Characteristic } & \multicolumn{4}{|c|}{ Fuel types } \\
\cline { 2 - 5 } & \multicolumn{2}{|c|}{ Liquid } & \multicolumn{2}{c|}{ Gaseous } \\
\cline { 2 - 5 } & diesel & gasoline & compressed & liquified \\
\hline \multirow{2}{*}{$L_{0}$} & 0,4994 & 0,5168 & 10,721 & 23,762 \\
\cline { 2 - 5 } & \multicolumn{2}{|c|}{$\mathrm{kmol} / \mathrm{kg}$} & \multicolumn{2}{|c|}{$\mathrm{kmol} / \mathrm{kmol}$} \\
\hline \multirow{2}{*}{$H_{u}$} & $42,5 \cdot 10^{6}$ & $44 \cdot 10^{6}$ & $33,78 \cdot 10^{6}$ & $44,8 \cdot 10^{6}$ \\
\cline { 2 - 5 } & \multicolumn{3}{|c|}{$\mathrm{J} / \mathrm{kg}$} & \multicolumn{2}{c|}{$\mathrm{J} / \mathrm{m}^{3}$} \\
\hline
\end{tabular}

To simplify the calculations of the theoretical coefficient of molecular variation of the fuel mixture at the average values of the fuel composition characteristics (see Tables 2 to 4), the dependences of $\beta$ on the relative air excess ratio $\bar{\alpha}$ are calculated [4] and represented (table 5). 
Table 3. Average values of elements $(\mathrm{C}, \mathrm{H}, \mathrm{O})$ forming part of liquid fuels $[2,5]$

\begin{tabular}{|c|c|c|c|}
\hline \multirow{2}{*}{ Fuel types } & \multicolumn{3}{|c|}{ Average element composition, kg/ kg } \\
\cline { 2 - 4 } & $\mathbf{C}$ & $\mathbf{H}$ & $\mathbf{O}$ \\
\hline diesel fuel & 0,87 & 0,126 & 0,004 \\
\hline gasoline & 0,855 & 0,145 & - \\
\hline
\end{tabular}

Table 4. Average values of the elements $(\mathrm{C}, \mathrm{H}, \mathrm{O})$ forming part of gaseous fuels $[2,5]$

\begin{tabular}{|c|c|c|c|c|c|c|c|c|c|c|}
\hline \multirow{2}{*}{$\begin{array}{c}\text { Types of } \\
\text { gaseous fuel }\end{array}$} & \multicolumn{10}{|c|}{ Component composition by weight,\% } \\
\cline { 2 - 11 } & $\mathbf{C H}_{\mathbf{4}}$ & $\begin{array}{c}\mathbf{C}_{2} \mathbf{H}_{\mathbf{4}} \\
+ \\
\mathbf{C}_{\mathbf{2}} \mathbf{H}_{\mathbf{6}}\end{array}$ & $\mathbf{C}_{\mathbf{2}} \mathbf{H}_{\mathbf{6}}$ & $\begin{array}{c}\mathbf{C}_{\mathbf{3}} \mathbf{H}_{\mathbf{6}} \\
+ \\
\mathbf{C}_{\mathbf{3}} \mathbf{H}_{\mathbf{8}}\end{array}$ & $\mathbf{C}_{\mathbf{3}} \mathbf{H}_{\mathbf{8}}$ & $\begin{array}{c}\mathbf{C}_{\mathbf{4}} \mathbf{H}_{\mathbf{8}} \\
+ \\
\mathbf{C}_{\mathbf{4}} \mathbf{H}_{\mathbf{1 0}}\end{array}$ & $\mathbf{C}_{\mathbf{4}} \mathbf{H}_{\mathbf{1 0}}$ & $\mathbf{C}_{\mathbf{5}} \mathbf{H}_{\mathbf{1 2}}$ & $\mathbf{C O}_{\mathbf{2}}$ & $\mathbf{O}_{\mathbf{2}}$ \\
\hline compressed & 0,95 & - & 0,04 & - & 0,015 & - & 0,01 & 0,003 & 0,01 & 0,01 \\
\hline liquified: & & & & & & & & & & \\
winter & - & 0,04 & - & 0,75 & - & 0,2 & - & - & - & - \\
summer & - & 0,6 & - & 0,34 & - & 0,6 & - & - & - & - \\
\hline
\end{tabular}

Table 5. Analytical dependencies $\beta$ on $\bar{\alpha}$

\begin{tabular}{|c|c|c|c|}
\hline Engine type & $\begin{array}{c}\text { Variation range } \\
\beta\end{array}$ & Formula & $R^{2}$ \\
\hline \multicolumn{4}{|c|}{ Liquid fuel } \\
\hline $\begin{array}{l}\text { with compression } \\
\text { ignition }\end{array}$ & $1,01-1,06$ & $0,1259 \bar{\alpha}^{3}-0,1136 \bar{\alpha}^{2}+0,04 \bar{\alpha}+1,007$ & 0,9968 \\
\hline $\begin{array}{l}\text { with forced } \\
\text { ignition }\end{array}$ & $1,04-1,115$ & $-0,0748 \bar{\alpha}+1,1155$ & 0,9995 \\
\hline \multicolumn{4}{|c|}{ Liquified petroleum gas (GOST standard 20448-80) } \\
\hline gas diesel engine & $1,007-1,019$ & $-0,012 \bar{\alpha}^{3}+0,0292 \bar{\alpha}^{2}-0,029 \bar{\alpha}+1,0187$ & 0,9997 \\
\hline $\begin{array}{c}\text { with forced } \\
\text { ignition }\end{array}$ & $1,02-1,024$ & $-0,0042 \bar{\alpha}+1,0239$ & 0,9953 \\
\hline \multicolumn{4}{|c|}{ Compressed petroleum gas (TU 51-16.6-83) } \\
\hline gas diesel engine & $1,001-1,003$ & $0,0015 \bar{\alpha}^{2}+0,0032 \bar{\alpha}+1,0027$ & 0,9949 \\
\hline $\begin{array}{c}\text { with forced } \\
\text { ignition }\end{array}$ & $1,003-1,0035$ & $0,0004 \bar{\alpha}^{2}-0,0009 \bar{\alpha}+1,0035$ & 0,978 \\
\hline
\end{tabular}

Note. $R^{2}$ is the square of the mixed correlation

\section{Discussion}

Under real conditions, the volume of gases is a mixture of combustion products of a fresh charge and gases not removed from the cylinder during the exhaust process. Quantitatively, the transformation of this parameter is taken into account by the actual coefficient of molecular change in the working mixture. Investigations [4] revealed a small discrepancy between the numerical values of the quantities when substituting the theoretical or actual coefficients of the molecular change in the working mixture. To preserve the logic in calculations with sufficient accuracy for practical calculations, one can use the theoretical coefficient of molecular variation of the working mixture (see Table 1). For engines operating on liquefied and compressed gaseous fuels, the values of the theoretical coefficient of molecular variation of the working mixture, depending on the relative coefficient of excess air (see Table 5), are practically constant and slightly different from one another in the entire range of changes in the operating conditions of the engine. 
As it turned out, the exhaust gas volume flow rate depends neither on the pressure and temperature of the air at the intake and after the cooler and compressor, nor on the engine speed, nor even the volume of the cylinders. A factor that takes into account atmospheric conditions, the value of the net calorific value, theoretically the required amount of air for complete combustion of the fuel, the purge factor, the rated power and the idling power are of a reference nature. The theoretical coefficient of molecular variation of the working mixture, the excess air factor and the effective efficiency of the engine can be represented depending on the relative power. Thus, the determination of the volume flow of exhaust gases reduces to finding the relative power of the engine.

\section{Conclusion}

Computer experiments performed on the process models of mixture formation and combustion of the working mixture in the internal combustion engines of cars with an error permissible for practical calculations reflect the real nature of the negative impact on the urbanized territory. The calculated values of the exhaust gases volume flow, as well as in the whole mass of emissions of pollutants into the atmospheric air by motor traffic, can serve as a preliminary estimate of environmental pollution [6].

\section{References}

1. V V.I. Smailys, Low emission diesel engines (Mechanical Engineering, Leningrad, 1972)

2. A.I. Kolchin, V.P. Demidov, Calculation of automobile and tractor engines (Higher education sc., Moscow, 2003)

3. N.H. Dyachenko, Theory of internal combustion engines (Mechanical Engineering, Leningrad, 1972)

4. L.K. Badalyan, Coll. of proc. and mat. of the All-Russian Sc. and Pr. Conf. "Technospheric Safety, Reliability, Quality, Energy and Resource Saving", 254 (2006)

5. A.M. Obelnitsky, E.A. Yegorushkin, Yu.N. Chernyavsky, Fuel, Lubricants and Cooling liquids (Polygran Publ., Moscow, 1995)

6. L.K. Badalyan, Sust. Dev. of Mount. Ter., 2(8), 5 (2011) 